\title{
RELAÇÃO PÚBLICO-PRIVADO NO CONTEXTO DE NEOCONSERVADORISMO NO BRASIL
}

\author{
Vera Maria Vidal Peroni ${ }^{1}$
}

RESUMO: O artigo traz elementos para o debate de como as particularidades do neoliberalismo (pós-crise de 2008) e suas relações com o neoconservadorismo redefinem as fronteiras entre o público e o privado, além de se materializarem nas políticas de educação básica no Brasil. Os processos de privatização do público podem ocorrer via execução e direção, nas quais o setor privado atua diretamente na oferta da educação, ou quando a atuação do privado ocorre na direção das políticas públicas ou das escolas, sendo que a propriedade permanece pública, mas o privado define seu conteúdo, com grandes implicações para a construção de uma sociedade democrática, pelo importante papel da educação nesse processo.

Palavras-chave: Relações público-privado em educação. Neoconservadorismo. Democratização da educação.

\section{PUBLIC-PRIVATE RELATIONSHIP IN THE CONTEXT OF THE NEOCONSERVETISM IN BRAZIL}

\begin{abstract}
This article brings forth material to the debate on how the particularities of neo-liberalism (post-2008 crisis) and its relations with neoconservatism redefine the boundaries between public and private, in addition to it materializing in basic education policies in Brazil. Privatization processes of the public can occur via implementation and administration in which the private sector acts directly in the provision of education, or when the private sector acts in the administration of public policies or schools, and although property remains public, the private sector defines its content, with great implications for the construction of a democratic society, due to the important role of education in this process.
\end{abstract}

Keywords: Public-private relations in education. Neoconservatism. Democratization of education.

$\mathrm{O}$ artigo tem como base a pesquisa Implicações da relação público-privado para a democratização da educação na América Latina: Argentina, Bolívia, Brasil, Chile, Uruguai e Venezuela, financiado pela Fundação de Amparo à Pesquisa do Estado do Rio Grande do Sul e Conselho Nacional de Desenvolvimento Científico e Tecnológico.

1.Universidade Federal do Rio Grande do Sul, Faculdade de Educação - Porto Alegre (RS), Brasil. E-mail: veraperoni@gmail.com

Nota da editora: Os conceitos, posicionamentos e o tratamento ético da pesquisa à qual se refere o texto publicado são de inteira responsabilidade da autora, não refletindo, necessariamente, a opinião do corpo editorial da Educação \& Sociedade. 


\title{
RELACIÓN PÚBLICO-PRIVADA EN EL CONTEXTO DEL NEOCONSERVADURISMO EN BRASIL
}

\begin{abstract}
RESUMEN: El articulo trae elementos para el debate, de cómo las particularidades del neoliberalismo (pos crisis 2008) y sus relaciones con el neoconservadurismo redefinen las fronteras entre lo público y lo privado, además de materializarse en las políticas de educación básica en Brasil. Los procesos de privatización de lo público, pueden ocurrir vía ejecución y dirección, donde el sector privado actúa directamente en la oferta de la educación, o cuando la actuación de lo privado ocurre en la dirección de las políticas o de las escuelas, siendo que la propiedad permanece publica, pero lo privado define su contenido con grandes implicaciones para la construcción de una sociedad democrática, a través del importante papel de la educación en este proceso.
\end{abstract}

Palabras-clave: Relaciones público-privadas en educación. Neoconservadurismo. Democratización en la educación.

\section{Introdução}

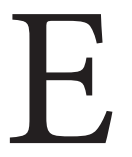

ste artigo apresenta elementos para o debate acerca das particularidades do neoliberalismo póscrise de 2008, com as reformas de segunda geração do Consenso de Washington, e sobre como suas relações com o neoconservadorismo redefinem as fronteiras entre o público e o privado e se materializam por meio das políticas educativas de educação básica no Brasil. Nesse sentido, apresenta formulações teóricas, construídas para aprofundar as análises, em nossas pesquisas, no que tange à relação entre o público e o privado na educação básica.

O principal foco que assumimos no debate é o da relação entre o público e o privado como um projeto societário em disputa, vinculando público ao coletivo e democrático e o privado, ao individualismo, tanto na perspectiva neoliberal quanto neoconservadora. Estão também presentes intelectuais orgânicos em think tanks e institutos, os quais elaboram e difundem conteúdos de suas propostas vinculados ao capital e ao neoconservadorismo. Nossas análises têm como base teórico-metodológica o movimento do real e, assim, do privado, inicialmente vinculado ao mercado. Aos fatos vivenciados no Brasil atualmente, acrescentamos o neoconservadorismo e o neofascismo.

A política educacional é analisada, em nossas pesquisas (PERONI, 2003; 2013; 2015; 2018), como a materialização das mudanças que ocorrem no movimento do real da sociedade nesse período particular do capitalismo. Assim que neste artigo analisamos o neoliberalismo pós crise de 2008, com as especificidades no papel do Estado para com as políticas educacionais. Nesse aspecto, a relação entre o público e o privado na educação não se limita apenas à propriedade, mas inclui também projetos societários em disputa de correlação de forças, que ocorrem tanto no Estado, quanto na sociedade civil, com profundas implicações para o papel da educação na construção de uma sociedade democrática (PERONI, 2018).

Os processos de privatização do público podem ocorrer via execução e direção, quando o setor privado atua diretamente na oferta da educação, ou na direção das políticas públicas ou das escolas, sendo que a propriedade permanece pública.

Verificamos, em nossa pesquisa atual (PERONI, 2018), que, no caso dos países latino-americanos que viveram ditaduras e lentamente consolidavam processos de democratização, em um processo de correlação de forças, também houve aumento de privatizações e diminuição de direitos. 
No caso brasileiro, o estado continua como o principal responsável pelo acesso à escola. Mais de 80\% das instituições de educação básica são públicas, mas a formação, as rotinas, o conteúdo pedagógico e de gestão da escola são definidos por instituições privadas (PERONI, 2015).

Desse modo, a privatização do público pode ocorrer com ou sem mudança de propriedade. É o que Rikowski (2017) traz acerca da privatização da e na educação, sendo que a privatização da educação, que ocorre via capitalização e privatização na educação, é a tomada de controle sobre a educação por parte das empresas e não envolve propriedade. Dá-se na disputa pelo conteúdo, em um projeto de restauração de classe. Para o autor, a privatização da educação, como capitalização, não se restringe apenas a uma privatização da educação, mas também sinaliza o avanço do capitalismo. É uma disputa pelo fundo público no sentido do lucro: a educação torna-se capital. Trata-se do desenvolvimento capitalista na educação. No caso deste artigo, abordamos a privatização na educação e a disputa pelo conteúdo e pelo controle da educação. (Rikowski, 2017).

É o que analisamos, em nossas pesquisas, com o envolvimento do privado via direção, considerando o não envolvimento da oferta, com a escola permanecendo pública. É o estado que paga o professor e, inclusive, define com que instituições serão feitas as parcerias ou a compra de pacotes educacionais. Já o setor privado passa a determinar a formação de professores, o monitoramento, o conteúdo trabalhado nas aulas e a gestão. Destacamos que o privado atua com o aval do público, que tem a mesma perspectiva política de classe e, por isso, o contrata. É o que temos aventado a privatização como política pública.

\section{Relação entre a Perspectiva de Público Vinculado ao Coletivo e ao Democrático e o Privado Vinculado a Indivíduo, Mercado ou Neoconservadorismo}

Ao analisar as possíveis implicações de determinados fenômenos à democracia, construímos, com base em Vieira (1998), Mészáros (2002) e Wood (2003), um conceito de democracia “[...] a democracia é entendida como a materialização de direitos em políticas coletivamente construídas na autocrítica da prática social" (PERONI, 2013, p. 1021).

Evaldo Vieira (1998) aponta que inexiste cidadania sem direitos e sem estado. Os direitos de cidadania nascem historicamente na sociedade, “[...] não há estágio democrático, mas há processo democrático pelo qual a vontade da maioria ou a vontade geral vai assegurando o controle sobre os interesses da administração pública", e, nesse sentido, segue o autor, "qualquer conceito de democracia, aliás há vários deles, importa em grau crescente de coletivização das decisões. [....] Quanto mais coletiva é a decisão, mais democrática ela é" (VIEIRA, 1998, p. 12).

Mészáros (2002, p. 991) traz o debate sobre controle social, ao afirmar que, “[...] no decurso do desenvolvimento humano, a função do controle social foi alienada do corpo social e transferida para o capital". Em uma sociedade para além do capital, deve haver o protagonismo dos sujeitos com foco no processo e não no produto, não se reforçando a separação entre quem pensa e quem executa na construção de políticas: “[...] programas e instrumentos de ação sociopolíticos verdadeiramente adequados só podem ser elaborados pela prática social crítica e autocrítica no curso do seu efetivo desenvolvimento" (MÉSZÁROS, 2002, p. 1008).

Wood (2003), ao realizar o debate sobre a não separação entre o econômico e o político, destaca que o mundo material é um produto histórico, e as relações de produção tomam formas jurídicas e políticas particulares. Agregamos, assim, a importância da materialização de direitos em políticas educacionais como parte do conceito de democracia.

Lowy (2016) aponta que, na história mundial, nos dois últimos séculos, a democracia é que foi o excepcional, um peso para o estado, para as classes dominantes e o capital financeiro. Ele conclui que, no 
Brasil, “[...] mesmo democracia de baixa intensidade era intensa demais para as classes dominantes e o capital financeiro" (LOWY, 2016, p. 61).

Relações baseadas em princípios democráticos são construídas por meio da experiência (THOMPSON, 1981). Com efeito, a educação exerce relevante papel no processo de construção de uma sociedade democrática.

Destacamos ainda as implicações para a democracia e a naturalização do individualismo e da censura (LIMA, 2017) vividas nesse período em nosso país. Observamos, em pesquisas sobre o tema, que institutos que fazem parcerias com escolas públicas têm como conteúdo de suas propostas o individualismo e a sua materialização, como competitividade, premiação e meritocracia. Esse é o caso, por exemplo, da gestão para o sucesso do Instituto Ayrton Senna (PERONI, 2011; PERONI; CAETANO; LIMA, 2017), da gestão para resultados do Instituto Unibanco (CAETANO, 2018), do curso gestão para aprendizagem da Fundação Lemann (PERONI; OLIVEIRA, 2019) ou do Sistema de Ensino Aprende Brasil com material didático, com o slogan Educação para Vencer, do Sistema Positivo (CARVALHO, 2018). Salientamos, igualmente, o controle que os institutos exercem sobre o trabalho do professor e o desempenho dos estudantes via Sistemas de Monitoramento, como é o caso do Sistema Ayrton Senna de Informação (SIASI) do Instituto Ayrton Senna, do Sistema de Monitoramento Educacional do Brasil (simeB) do Sistema Positivo, do Sistema de Gestão de Projetos (SGP) e do Ambiente Virtual de Aprendizagem (AVA) do Instituto Unibanco.

Também a escolha dos pais dentre as propostas das escolas charter (ADRIÃO, 2014) ou de homeschooling (ADRIÃO; GARCIA, 2017) constitui forma de individualismo, ao se defender o que é bom apenas para seu filho, sem tratar da importância da escola para um projeto societário, em sua qualidade de instituição.

\section{Privado com Base no Individualismo: Novo Neoliberalismo, Neoconservadorismo e Neofascismo}

Puello-Socarrás (2008) trabalha as particularidades do neoliberalismo, no pós-crise de 2008:

El neoliberalismo hoy por hoy lejos de agotarse se reedita. Presenciamos alguna suerte de reactualización que se prolonga en el tiempo y en el espacio, tanto a nivel global como local. Aunque -también es cierto que, a su vez - las crisis neoliberales manifiestan cada vez más que los márgenes de su autogestión van estrechándose con la profundización de sus contradicciones. (PUELLO-SOCARRÁS, 2008, p. 81)

Para o autor, nesse contexto, o estado redefine seu papel passando de estado mínimo para estado empresarial, definido pelas reformas de segunda geração do Consenso de Washington: "[...] reformas de Segunda Generación, las cuales dirigen su interés en torno a las reformas políticas e institucionales han estado dominadas por el tema de la reforma estatal y sus implicaciones" (PUELLO-SOCARRÁS, 2008, p. 107).

A reforma estatal proposta desvincula o público do estatal e reforça um espaço público-privado, que tem o mercado como paradigma:

Así se promociona un dominio que desvincula 'lo público' de 'lo estatal' en una especie de éspacio público-privado', o como se lo ha denominado un 'espacio público no-estatal' que resulta abiertay fundamentalmente mercantil (como el mismo status ontológico del Mercado: un dominio que no 
es exclusivamente privado sino estrictamente público-privado, es decir, un locus público donde las mercancías tienen la posibilidad de intercambiarse entre ellas para posteriormente privatizarse). (PUELLO-SOCARRÁS, 2008, p. 108)

O governo que, além de repassar para o público não estatal a execução das políticas sociais, tem características gerenciais, constituindo o que o autor chama de governo empresarial, que tem como proposta o cliente de serviços a ser buscado no mercado. Isso porque o governo evita a prestação direta de serviços, fugindo do que a teoria neoliberal critica como monopólio do estado na execução de políticas:

Este tipo de actuación gubernamental estaría definida por 'lo empresarial'. El Gobierno empresarial - plantean - es un tipo de gobierno inspirado en el cliente. [...] El gobierno empresarial limitaría su rol a la regulación pública, evitando la prestación directa de los servicios sociales, manteniendo niveles óptimos de competencia e impidiendo al máximo las situaciones monopólicas $y$ las interferencias en el mercado. (PUELLO-SOCARRÁS, 2008, p. 113)

O autor aponta algumas consequências sociais dessa proposta, como o foco no individualismo, já que o empreendedor é sempre o indivíduo, além do esfumaçamento das relações capital-trabalho e da flexibilização laboral, inclusive as que acontecem via economia solidária e cooperativas de trabalho.

[...] llaman la atención la sospechosa 're-invocación' y el protagonismo público que han ganado distintas formas de Voluntariado y actividades de ONG's y de la Economía Solidaria, el conocido 'tercer sector' en el cual se han recodificado distintas acciones socio-económicas pero que se han dirigido a desestructurar el campo estatal y todo lo que ello significa, sobre todo, en materia de derechos constitucionales y la seguridad social, específicamente, frente a las regulaciones laborales prevalecientes que suponen obstáculos y 'cargas' para la actual acumulación capitalista del neo-liberalismo, favoreciendo al Capital. (PUELLOSOCARRÁS, 2008, p. 97)

É importante resgatar que o Brasil já materializava essa proposta em 1995, com o Plano Diretor da Reforma do Estado, aprovado durante o governo de Fernando Henrique Cardoso. O plano apresentava as políticas sociais como atividades não exclusivas do estado e, assim, elas não pertenciam mais ao núcleo estratégico, devendo ser exercidas pela sociedade por meio da privatização de distintas formas: privatização, que, conforme o plano, é a transferência para o mercado dos serviços lucrativos; a terceirização, que é a passagem para o setor privado de serviços auxiliares ou de apoio, e a publicização, que é o repasse para o setor público não estatal dos serviços sociais e científicos que o Estado presta (BRASIL, 1995). As políticas sociais foram consideradas serviços não exclusivos do estado e, dessa forma, de propriedade pública não estatal ou privada.

Laval e Dardot (2017) afirmam que a crise é estrutural. Logo, ela atinge a todos. Os autores também ressaltam que, ao invés de se fragilizar, o neoliberalismo se alimenta da crise:

[...] el sistema esta em crisis y su crisis es tan crónica como total, se extiende a todos los aspectos de la realidad puesto que la lógica neoliberal no deja a salvo a ninguna dimensión de la existencia humana. Pero la fórmula significa también que el sistema se alimenta de la crisis y que se refuerza mediante la crisis [...] obligan a los gobiernos a someterse a las consecuencias de las políticas anteriores que ellos mismos han llevado a cabo. (LAVAL; DARDOT, 2017, p. 31) 
Para os autores, o novo neoliberalismo se reinventou após a crise financeira de 2008, que passou a ser a justificativa da diminuição de direitos materializados em políticas sociais:

[...] o novo neoliberalismo é a continuação do antigo de maneira pior. O marco normativo global que insere indivíduos e instituições dentro de uma lógica de guerra implacável, reforça-se cada vez mais e acaba progressivamente com a capacidade de resistência, desativando o coletivo. (LAVAL; DARDOT, 2019, p. 11)

O novo neoliberalismo alimenta-se da crise. É assim que ele fomenta o neoconservadorismo e diminui a democracia, única forma de solucionar a crise:

Esta natureza antidemocrática do sistema neoliberal explica em grande parte a espiral sem fim da crise e o aceleramento diante de nossos olhos do processo de desdemocratização, pelo qual a democracia se esvazia de sua substância, sem que se suprima formalmente. (LAVAL; DARDOT, 2019, p. 11).

Analisando o Brasil, os autores advertem que:

Na realidade, o brasileiro não é um caso isolado, por mais que lá os recursos da manobra sejam mais visíveis que em outras partes, sobretudo após a vitória de Bolsonaro como ponto de chegada do processo. O fenômeno, para além de suas variações nacionais, é geral: é no interior do marco formal do sistema político representativo que se estabelecem dispositivos antidemocráticos de uma temível eficácia corrosiva (LAVAL; DARDOT, 2019, p. 3).

Para Boito (2019), estamos vivenciando, no Brasil, um período de características neofascistas. Para o autor, dentre outras características, o "[...] fascismo é um gênero; o fascismo alemão e italiano, de um lado, e o fascismo brasileiro, de outro, são, ambos, espécies desse gênero. Estou chamando o primeiro de fascismo original e o segundo de neofascismo" (BOITO, 2019, p. 2).

O neoconservadorismo tem sido outro elemento importante para entendermos esse período particular do capitalismo. Para Laval e Dardot (2017), o neoliberalismo é instrumental ao novo neoliberalismo. Já para Harvey (2008), existem especificidades entre o neoliberalismo e o neoconservadorismo. Como semelhanças, o autor aponta que ambos são favoráveis ao poder corporativo, à iniciativa privada, à restauração do poder de classe, à desconfiança da democracia e à governança pela elite. No entanto, existem diferenças, como a preocupação com a ordem em resposta ao caos, e o neoconservadorismo defende uma moralidade inflexível como cimento social, o que não é uma característica do neoliberalismo. Para o autor, a diminuição das políticas sociais, o aumento do desemprego e dos ajustes estruturais e a exacerbação da competitividade e do individualismo provocam o caos social e civilizatório; o neoconservadorismo responde a esse problema com maior coerção social. É essa a realidade que temos vivenciado no Brasil nos últimos anos.

Lacerda (2019) também nos ajuda a entender o neoconservadorismo. Para a autora, é

Um movimento político que forjou um ideário privatista (defende o predomínio do poder privado da família e das corporações), antilibertário (a favor da interferência pública em aspectos da vida pessoal), neoliberal (contra a intervenção do Estado para a redução das desigualdades), conservador (articula-se em reação ao Estado de bem-estar, ao movimento feminista e LGBT) e de direita (se opõe a movimentos reivindicatórios que buscam maior 
igualdade de direitos). [...] O eixo da linguagem neoconservadora é a ideia de privatização. Seja no sentido de garantir o total livre mercado, livre de ingerências estatais; seja no sentido de se manter intocado o poder patriarcal (LACERDA, 2019, p. 58).

Moll Neto (2010, p. 65) expõe as raízes do neoconservadorismo․ Para o autor, a “[...] ideologia neoconservadora resgatou e reconstruiu pressupostos de correntes conservadoras que os antecederam, basicamente do velho conservadorismo e do libertarianismo ". O autor ressalta que a questão principal de união entre os grupos era o individualismo. Para ele, “[...] nada justificava projetos estatais que interferissem na vida das pessoas e limitassem as liberdades, sobretudo a econômica” (MOLL NETO, 2010, p. 67).

A retirada de direitos sociais e trabalhistas e a lógica de mercado e neoliberal na esfera pública não foram simplesmente aceitas pela população. Tratou-se de um longo trabalho de sujeitos individuais e coletivos, organizados ou não em redes nacionais e internacionais.

\section{Think tanks e Institutos: Sujeitos e Relações Vitais para a Produção e a Disseminação do Ideário Neoliberal e Neoconservador}

Moll Neto (2010) ressalta, ainda, que, a partir da crise da década de 1970, iniciou-se uma mobilização neoconservadora, que ocorreu principalmente por meio da criação de think tanks: “os empresários da nova direita organizaram fundações para reunir capital para apoiar e financiar universidades, pesquisas e centros de estudo (Think Thanks) a fim de elaborar projetos políticos nacionais" (MOLL NETO, 2010, p. 69). O autor sublinha a importância das business policy organizations (BPOs) neoconservadoras e ultraneoconservadoras com preponderância das elites sulistas dos Estados Unidos, sobretudo do Sun Belt, financiando instituições como a Business Roundtable, o American Enterprise Institute, a Heritage Foundation e o Hoover Institution, que contribuíram para a formulação e a divulgação do neoconservadorismo.

Rocha (2017) observa que o formato de atuação inaugurado pela Heritage Foundation marcou o nascimento de um outro tipo de organização nos Estados Unidos: os think tanks "ativistas".

Sua missão é formular e promover políticas públicas conservadoras baseadas na defesa da livreempresa, do Estado mínimo, da liberdade individual, dos valores tradicionais americanos e da importância de uma forte defesa nacional. Para conseguir influenciar o máximo possível o processo político nesta direção e obter o maior número de vitórias possível na chamada 'batalha das ideias', suas estratégias de marketing são direcionadas para um público alvo composto por membros do Congresso, membros de equipes parlamentares, formuladores de políticas públicas no poder executivo, mídia nacional, e comunidades acadêmicas. (ROCHA, 2017, p. 98).

Moraes (2015) pontua que os milionários americanos disseminaram a cultura de mercado, entre outros fatores, como parte do esforço de mudar a imagem do empresariado perante a opinião pública e modelar o ambiente político, por meio dos think tanks:

[...] a 'novíssima direita' cria e multiplica think tanks e aparatos de mídia (impressa, eletrônica, virtual etc.) para modelar o ambiente político. De outro lado, operando também como lobbies (pressionando para aprovação de certas políticas ou para o direcionamento das já existentes), 
eles conseguem esse mesmo objetivo: policies make polity, diz a sentença. Assim, por exemplo, ocorre com o fato de determinados programas públicos (provisão de saúde, educação etc.) serem financiados pelo público, mas 'entregues' através de canais privados: isto os faz, ainda que públicos, reconhecíveis pelo usuário como privados. (MORAES, 2015 p. 240)

Rocha (2017) ressalta, também, a importância da Atlas Network ${ }^{3}$, formada com o intuito inicial de fornecer uma espécie de central coordenadora para as organizações de direita criadas até então.

A atuação da Atlas na América Latina durante os anos 1980 e início da década de 1990 marcou o primeiro momento no histórico de atuação de think tanks 'ativistas' de direita na América Latina. Seja auxiliando na fundação de organizações novas ou incorporando think tanks criados por elites locais, especialmente por grupos de empresários nacionais e estrangeiros, como é o caso do Brasil com IEE [Instituto de Estudos Empresariais] e o Instituto Liberal. (ROCHA, 2017, p. 272)

No caso da educação brasileira, destacamos a atuação de dois think tanks: o Instituto Millenium e a Fundação Getulio Vargas (FGV). A atuação do primeiro se dá pela vinculação com as questões econômicas e por ter integrantes em seus quadros que exercem funções no governo federal, além de sua atuação na educação, por meio do Instituto Millenium (Imil) na sala de aula, que realiza palestras nas universidades com integrantes do instituto e a produção de livros infantis, como Antônio e o segredo do universo em breves lições e Anya e o mistério do sumiço do cãozinho Galt (COMUNICAÇÃO MILLENIUM, 2019), inspirados nas ideias defendidas por Ludwig Von Mises. A atuação do segundo ocorre pela sólida atuação no país e, especialmente, por ter criado, recentemente, um segmento definido como o primeiro think tank brasileiro de política educacional, o Centro de Excelência e Inovação em Políticas Educacionais (Ceipe).

No ano de 2016 é inaugurado no Brasil o Ceipe, lotado na Escola de Administração Pública e de Empresas (Ebape) da FGV. O Ceipe está vinculado ao Programa de Política Educacional Internacional da Universidade de Harvard e conta com o apoio do Instituto Brookings. No Brasil seus parceiros são: a Fundação Lemann, o Instituto Unibanco, o Instituto Natura, o Itaú Social, a Fundação Maria Cecília Souto Vidigal, o Itaú BBA e a Omidyar Network. Compõem o conselho da organização representantes da Fundação Lemann, da Fundação Maria Cecília Vidigal, do Instituto Unibanco, da Aondê Educacional, da Granergia, do Todos pela Educação e representantes da FGV. De acordo com os dados disponibilizados pela FGV, trata-se do primeiro think tank brasileiro especializado em política educacional que pretende influenciar a organização das políticas nas secretarias de educação no país (PERONI; MENDES, 2020, p. 77).

Com os think tanks, verificamos que, tanto no Estado, quanto na sociedade civil, existem sujeitos, com objetivos de classe, que defendem projetos com interesses vinculados ao mercado ou ao neoconservadorismo, sustentando projetos mais individualistas do que democráticos.

A construção da democracia é um longo caminho e questionamos as implicações da mercantilização da educação pública, assim como dos princípios conservadores e a censura implícita e explícita que estamos vivenciando nesse período histórico, para esse processo de construção.

Dessa forma, o privado atua de diversas formas e em todos os níveis, desde as instâncias de decisão, ministérios, secretarias de educação até a sala de aula. 


\section{Múltiplas Formas de Materialização do Privado na Educação Básica Pública no Brasil}

No Brasil, o estado se mostra historicamente vinculado aos interesses privados (FERNANDES, 1985, 1987; PIRES, 2013). Após o último período de ditadura, a partir de meados dos anos 1980, vivenciamos um período de construção democrática, no qual participação, coletivização das decisões e direitos sociais materializados em políticas entraram para a pauta em um processo de alargamento do público, vinculado ao democrático - inclusive na educação. Ao mesmo tempo, os processos de neoliberalismo, reestruturação produtiva e financeirização redefiniam o papel do estado, avançando em políticas de austeridade que reduziam direitos sociais. Assim, tanto quanto avançávamos lentamente em alguns direitos materializados em políticas educacionais, progredíamos na privatização do público.

No Brasil, o processo de privatização do público ocorre tanto pela direção como pela execução, ou mesmo por meio de ambas. No processo de direção, destacamos o Movimento Todos pela Educação, em que os empresários buscam influenciar o governo federal, tanto na pauta educacional quanto na venda de produtos educativos (BERNARDI; UCZAK; ROSSI, 2018b, MARTINS 2013). No que concerne à privatização via execução, destacamos a expansão da oferta da educação infantil via creches comunitárias (SUSIN; MONTAÑO, 2018), nos Programas de Educação de Jovens e Adultos, como o Brasil Alfabetizado (COMERLATTO; MORAES, 2013), e de educação profissional, como o Programa Nacional de Acesso ao Ensino Técnico e Emprego (Pronatec) (RODRIGUES, 2018).

Em geral, instituições privadas definem o conteúdo da educação e executam sua proposta por intermédio da formação, da avaliação do monitoramento, da premiação e de sanções que permitem um controle de que seu produto será executado. Nesses casos, a privatização ocorre via execução e direção. Parcerias entre os Instituto Unibanco (CAETANO, 2018) e Ayrton Senna (PERONI, 2011; COMERLATTO, 2018) com escolas públicas trabalham no propósito de definir políticas, com a concepção, o acompanhamento e a avaliação da educação nas redes públicas parceiras.

Sobre a presença do mercado na educação, Rikowski (2017, p. 395) ressalta que

[...] a privatização na educação não é essencialmente sobre educação. Trata-se do desenvolvimento do capitalismo e do aprofundamento do domínio do capital em instituições específicas (escolas, faculdades, universidades etc.) na sociedade contemporânea.

Para o autor:

As instituições de educação e de formação de professores estão envolvidas na produção social da força de trabalho (RIKOWSKI, 1990). Assim, quando são privatizadas, as atividades, processos e formas pedagógicas envolvidas na produção de força de trabalho também são necessariamente privatizadas. (RIKOWSKI, 2017, p. 395)

O autor enfatiza, ainda, que existem duas formas básicas de privatização: a direta, que se refere à propriedade e compete à conversão da receita do estado em lucro privado; e a na educação, que se refere às formas de controle sobre a educação por parte das empresas.

A privatização da educação ocorre por meio da capitalização, quando o setor privado transforma o fundo público em lucro: “[...] a política de privatização educacional (ou de 
qualquer outra forma) é a obtenção de lucros, que por sua vez se baseia na capitalização de instituições e serviços educacionais; educação tornando-se capital. Trata-se do desenvolvimento capitalista na educação" (RIKOWSKI, 2017, p. 401).

O autor critica a ideia de que repassar para o setor privado a educação a tornaria mais eficiente e produtiva:

"[...] a noção de que a privatização da educação é mais eficiente do que o prestador estatal, como defendido por muitos de seus apoiadores, é contraintuitiva. O lucro é um custo extra que os prestadores públicos não possuem [...]" (RIKOWSKI, 2017, p. 400).

Rikowski adverte ainda que o lucro ocorre precarizando o trabalho docente:

“[...] a necessidade de apertar orçamentos e aumentar a carga horária dos professores torna-se uma necessidade pós-privatização, e a busca de outras medidas de redução de custos torna-se uma prioridade" (RIKOWSKI, 2017, p. 400).

É isso o que exatamente verificamos no documento do Banco Mundial Um ajuste justo: análise da eficiência e equidade do gasto público no Brasil. Conforme essa publicação, o poder público deve investir menos em educação: “[...] uma análise de eficiência intermunicipal demonstra que o desempenho atual dos serviços de educação poderia ser mantido com 37\% menos recursos no Ensino Fundamental” (BANCO MUNDIAL, 2017, p. 13). O documento também aponta que o estado gasta muito e gasta mal: "as crescentes despesas públicas e a queda nos números de matrículas públicas resultam em um maior gasto por estudante e em razões aluno-professor ineficientes" (BANCO MUNDIAL, 2017, p. 121).

Esse documento responsabiliza os professores pela reprovação e pela baixa qualidade de ensino. "Além de uma razão aluno-professor relativamente baixa, o sistema público de educação no Brasil é caracterizado por baixa qualidade dos professores e pelos altos índices de reprovação. Todos esses fatores levam a ineficiências significativas." (BANCO MUNDIAL, 2017, p. 121). Por fim, assinala que os professores são mal formados, mal contratados e os maiores culpados pelas ineficiências da educação:

O magistério permanece uma profissão desprestigiada. Os requisitos para ingresso em cursos de licenciatura são fracos e a formação é de baixa qualidade. E além da pouca seletividade na contratação de professores para os sistemas educacionais estaduais e municipais, os salários não são vinculados ao desempenho. A mudança desse paradigma exigirá reformas coordenadas de políticas públicas nas esferas federal, estadual e municipal. As tendências demográficas, no entanto, oferecerão uma grande oportunidade para elevar o nível dos professores e da qualidade da educação ao longo da próxima década, pois estima-se que a população em idade escolar diminua em 25\% entre 2010 e 2025. Isso, aliado a um grande número de professores que irão se aposentar nos próximos anos, permitirá uma maior seleção na contratação de um número menor de professores que serão necessários para substituir os que estarão se aposentando. (BANCO MUNDIAL, 2017, p. 127)

Viviane Senna, presidente do Instituto Ayrton Senna, aponta nessa mesma direção, quando frisa o suposto despreparo dos docentes, razão pela qual os conteúdos propostos pelo Instituto devem ser fortemente estruturados: 
Os materiais são fortemente estruturados, de maneira a assegurar que mesmo um professor inexperiente, ou com preparação insuficiente - como é o caso de muitos professores no Brasil -, seja capaz de proporcionar ao aluno um programa de qualidade, com elevado grau de participação dos alunos na sala de aula, na escola e na comunidade. (SENNA, 2000, p. 146)

O conceito, cada vez mais propalado, é o de que a educação pública, no Brasil, é precária, e o privado deve "contribuir" para elevar sua qualidade, trazendo os princípios de mercado, que são mais eficientes e produtivos. Isso é parte do diagnóstico neoliberal de que o setor público é o culpado pela crise e o âmbito privado deve ser o parâmetro de qualidade, expresso no documento do Banco Mundial e na fala da presidente do Instituto Ayrton Senna.

É importante destacar que o Banco Mundial reforça a ideia de diminuição de gastos em educação, ao mesmo tempo que fomenta a parceria com instituições privadas. Tais vínculos, no entanto, oneram sobremaneira os estados e municípios.

Adrião e Domiciano (2018, p. 8) demonstram, em estudo, “[...] o crescimento do investimento em educação, principalmente entre 2010 e 2014 (140\%), é certo também que os recursos de MDE destinados ao setor privado acompanharam tal incremento - triplicaram entre 2010 e 2014 ".

Nesse mesmo sentido, Rikowski (2017, p. 403) aborda a importância da capitalização da educação, como um devir do capital: "em relação à educação, o Devir do capital refere-se, portanto, aos processos envolvidos em sua capitalização: a educação tornando-se capital”. O autor aponta mais elementos de como ocorre o processo de capitalização da educação:

A capitalização da educação inclui pelo menos os seguintes desenvolvimentos futuros (mercantilização também essencial): geração e formação das duas formas de mercadorias (força de trabalho e classe geral), como observado anteriormente e a mercantilização (marketization) onde os mercados educacionais devem ser estabelecidos. (RIKOWSKI, 2017, p. 404)

E conclui que,

[...] a privatização da educação, como uma dimensão de sua capitalização, indica uma fase mais elevada do capitalismo em comparação às instituições e processos públicos de ensino. Portanto, bloquear a privatização é, ao mesmo tempo, prejudicar o desenvolvimento capitalista na educação, como restringir e destruir qualquer outro momento da capitalização da educação. A política anticapitalista na educação, portanto, deve se concentrar nessas considerações, que têm o efeito de atacar o desenvolvimento capitalista. (RIKOWSKI, 2017, p. 408)

Sobre a segunda forma de privatização, apresentada por Rikowski (2017), que envolve o controle das escolas, já temos importantes pesquisas no Brasil. Destacamos: o mapeamento realizado por Adrião (2018) sobre formas de privatização em três dimensões - gestão da educação, oferta educacional e currículo; a pesquisa nacional Análise das consequências de parcerias firmadas entre municípios brasileiros e a Fundação Ayrton Senna para a oferta educacional (ADRIÃO; PERONI, 2011); o mapeamento da inserção do setor privado nas redes estaduais de educação (2005-2015), realizado pelo Grupo de Estudos e Pesquisas em Política Educacional (GREPPE) da Universidade Estadual de Campinas (Unicamp) ${ }^{4}$, e a pesquisa Redefinições das fronteiras entre o público e o privado: implicações para a democratização da educação, realizada pelo Grupo de Pesquisa: Relações entre o Público e o Privado na Educação (GPRPPE) da Universidade Federal do Rio Grande do Sul (UFRGS) . Sobre a privatização do público na direção das políticas educativas atuais, 
destacamos sua atuação na Base Nacional Comum Curricular (PERONI; CAETANO; ARELARO, 2019; BERNARDI; UCZAK; ROSSI, 2018a), na educação domiciliar (ADRIÃO; GARCIA, 2017) e na reforma do ensino médio (PERONI; CAETANO; LIMA, 2017).

Orellana (2017, p. 14) adverte para a especificidade latino-americana: “[...] es fundamental aclarar que el neoliberalismo no encuentra en el continente una educación pública moderna definitiva o universalmente desarrollada, sino que halla precisamente, como elemento más saliente, su incapacidad de constituirse en tal". O autor aponta para a importância de discutir o neoliberalismo como a mercantilização total da vida, uma vez que o debate sobre a privatização da educação não deve ser nem apenas moral e nem no sentido de atingir ou não os objetivos específicos de melhoria dos índices educacionais:

\begin{abstract}
Si se quiere comprender la transformación reciente de la educación en América Latina, el debate debe ser planteado de otro modo. No en un sentido moral ni residual, puesto que la educación de mercado tanto como la pública han de analizarse como proceso real antes que ideal o normativo; ni tampoco en un sentido puramente técnico, pues los modos en que los indicadores son construidos y el presupuesto epistemológico que subyace a ellos establece, desde ya, los límites de esa discusión. Por supuesto, no se trata de despreciar la estadística, sino de criticar la idea que la educación es, en lo fundamental, una producción técnica de resultados objetivos medibles como competencias. La educación es, ante todo, un fenómeno social y político. Una manera de romper esta estructura de la discusión es criticar sus conceptos madre o sus constantes. (ORELLANA, 2018, p. 16)
\end{abstract}

Sobre pesquisas que envolvem a relação entre público e privado em países latinoamericanos, destacamos: a realizada pela Campaña Latinoamericana Por el derecho a la educación, mapeo sobre tendências de la privatización de la educación en América Lalina y el Caribe (CAMPAÑA LATINOAMERICANA..., 2015); a pesquisa coordenada por Antony Verger, Mauro Moschetti e Clara Fontdevila (2017), da Universitat Autônoma de Barcelona, La privatización educativa en America Latina Una Cartografia de políticas, tendencias y trayectorias; e a pesquisa de Cristián Bellei e Víctor Orellana, da Universidade do Chile, What Does 'Education Privatisation' Mean? Conceptual Discussion and Empirical Review of Latin American Cases (BELLEI; ORELLANA, 2014), além da pesquisa Implicações da relação público-privado para a democratização da educação na América Latina: Argentina, Bolívia, Brasil, Chile, Uruguai e Venezuela, realizada pelo GPRPPE (PERONI, 2018).

Historicamente, foram muito tênues as linhas divisórias entre o público e o privado nos países latino-americanos (IANNI, 1988), desde o início do processo de colonização até os dias atuais. O próprio estado assumiu um espaço por vezes voltado aos interesses privados, e a democratização da educação pública ainda é um longo caminho em construção.

\title{
Considerações Finais
}

Com base no entendimento de que o estado, assim como o capital, consiste numa relação ou processo em um movimento de sujeitos em correlação de forças de classes sociais e projetos societários distintos, analisamos como a lógica mercantil e neoconservadora têm participado da direção e da execução das políticas sociais - e como a presença desses sujeitos influencia cada vez mais nas políticas educacionais.

Entendemos que direitos sociais materializados em políticas são parte do conceito de democracia, mas, para que esse direito se materialize, o poder público deve ter o dever de assegurá-lo. 
Questionamos as posições que repassam para a sociedade ou ao indivíduo a execução do que seriam seus direitos conquistados historicamente, assim como o poder público, que repassa para instituições privadas o conteúdo da proposta educacional.

Destacamosasconsequências de um projeto societário edeeducação, combaseno individualismo, nãomais tendoocoletivismo como paradigma. Aolongo dotexto, verificamosqueo foconoindividualismofoi capaz de unir conservadores e libertários no neoconservadorismo, e destacamos que o individualismo é uma posição comum também ao neoliberalismo e ao neoconservadorismo. O sucesso e o fracasso são considerados individuais, por meio das virtudes empreendedoras do indivíduo.

É importante destacar as especificidades de um país recém-desenredado de uma longa ditadura, que está timidamente dando os primeiros passos na conquista por direitos materializados em políticas, quando vivenciou os processos de naturalização da perda de direitos no período de ajuste fiscal e de implementação das estratégias de superação da crise do capital de neoliberalismo, a reestruturação produtiva, a financeirização e o neoconservadorismo, que redefinem o papel do estado como principal garantidor dos direitos sociais materializados em políticas.

Se, por um lado, o Brasil avançou na materialização de direitos em políticas, por outro avançou também no processo de privatização do público, tanto pela execução como pela direção das políticas educacionais. Não temos um histórico democrático e a privatização do público é naturalizada em nossa cultura. No entanto, no período pós-ditadura, em um contexto de correlação de forças com essa lógica historicamente instaurada, no período de democratização, teve início um movimento de repensar o público e o Estado, com a participação efetiva da sociedade.

A participação envolve um longo aprendizado, e o papel da escola, nesse processo, é fundamental para a construção da democracia. Portanto, quando criticamos as entidades privadas, que definem ou executam as políticas públicas, focamos nas instituições que trazem a lógica de mercado, com perdas para a concepção de democracia, como coletivização das decisões, conforme abordamos no conceito de democracia apresentado no início do artigo. Igualmente, questionamos a perda da responsabilidade doestado no processo de execução como a responsável pelas políticas universais e a perda da concepção de democracia como direitos sociais, materializados em políticas universais (para todos e com qualidade) e da democracia como igualdade social materializada em políticas públicas.

Com base nos conceitos de que o Estado e o capital são entendidos como relação ou processo em um movimento de sujeitos em correlação de forças de classes sociais e projetos societários distintos, percebemos as redes como sujeitos em relação com objetivos de classe. Analisamos como a lógica mercantil tem participado ativamente da direção e da execução das políticas sociais, e como a presença desses sujeitos, que passam a influenciar fortemente nas políticas sociais, culmina numa inevitável diluição nas responsabilidades de materialização dos direitos em políticas sociais.

\section{Notas}

1. Os colunistas da revista National Review, em 1955, foram protagonistas de uma determinada reinterpretação e reconstrução da ideologia conservadora, que ficou conhecida como nova direita ou neoconservadorismo (MOLL NETO, 2010).

2. Os libertários reivindicam o estado mínimo não só na economia, mas também na vida pessoal (LACERDA, 2019, p. 54). 
3. A Atlas Network, ou Atlas Economic Research Foundation, é uma rede internacional de fundações sediada nos Estados Unidos, criada em 1981. É uma espécie de meta-think tank (AMARAL, 2015), especializada em fomentar a criação de novos think tanks, bem como coordenar as instituições já existentes. Atualmente conta com 509 instituições parceiras, sendo 98 na América Latina e 14 no Brasil. Disponível em https://www.atlasnetwork.org/ partners/global-directory/. Acesso em: 20 out. 2020

4. Disponível em https://www.greppe.fe.unicamp.br/pt-br/mapeamento_da_insercao_do_setor_privado_nas_redes_ estaduais_de_educacao. Acesso em: 3 nov 2020.

5. Disponível em https://www.ufrgs.br/gprppe/. Acesso em: 3 nov 2020.

\section{Referências}

ADRIÃO, T. Escolas Charters nos EUA: contradições de uma tendência proposta para o Brasil e suas implicações para a oferta da educação pública. Educação e Filosofia, Uberlândia, v. 28, n. 2014 ESP, p. 263-282, out. 2014.

ADRIÃO, T. Dimensões e formas da privatização da educação no Brasil: caracterização a partir de mapeamento de produções nacionais e internacionais. Currículo Sem Fronteiras, Portugal, Brasil, v. 18, n. 1, p. 8-28, jan./abr. 2018.

ADRIÃO, T.; DOMICIANO, C. A. A educação pública e as corporações: avanços e contradições em uma década de ampliação de investimento no Brasil. FINEDUCA - Revista de Financiamento da Educação, Porto Alegre, v. 8, n. 3, 2018.

ADRIÃO, T.; GARCIA, T. O. Educação a domicílio: o mercado bate à sua porta. Revista Retratos da Escola, Brasília, v. 11, n. 21, p. 393-413, jul./dez. 2017.

ADRIÃO, T.; PERONI, V. Análise das consequências de parceria firmadas entre municípios brasileiros e a Fundação Ayrton Senna para a oferta educacional. Rio Grande do Sul: Grupo de Pesquisa Relações entre o Público e o Privado em Educação, 2011. Disponível em https://www.ufrgs.br/gprppe/?page_id=77. Acesso em: 3 nov 2020.

AMARAL, M. A nova roupa da direita. Agência Pública, São Paulo, 23 jun. 2015. Disponível em https:// apublica.org/2015/06/a-nova-roupa-da-direita/. Acesso em: 29 out 2020.

BANCO MUNDIAL. Um ajuste justo: análise da eficiência e equidade do gasto público no Brasil. Washington, DC: [s.e.], 2017.

BELlEI, C.; ORELlANA, V. What Does 'Education Privatisation' Mean? Conceptual Discussion and Empirical Review of Latin American Cases. Santiago: Center for Advanced Research in Education \& Sociology Department of University of Chile, 2014.

BERNARDI, L. M.; UCZAK, L. H.; ROSSI, A. J. Relações do movimento empresarial na política educacional brasileira: a discussão da Base Nacional Comum. Currículo Sem Fronteiras, Portugal, Brasil, v. 18, n. 1, p. 29-51, 2018a.

BERNARDI, L. M.; UCZAK, L. H.; ROSSI, A. J. Relações do movimento empresarial na política educacional brasileira: a naturalização da associação público-privada. In: PERONI, V. M. V.; LIMA, P. V.; KADER, C. R. (org.) Redefinições das fronteiras entre o público e o privado: implicações para a democratização da educação. São Leopoldo: Oikos, 2018b. p. 115-124. 
BOITO, A. A terra é redonda e o governo Bolsonaro é fascista. A terra é redonda. 2019. Disponível em https:// aterraeredonda.com.br/a-terra-e-redonda-e-o-governo-bolsonaro-e-fascista/. Acesso em: 29 out 2020.

BRASIL. Presidência da República. Câmara da Reforma do Estado. Plano diretor da reforma do aparelho de estado. Brasília, DF: [s.e.], 1995. Disponível em http://www.bresserpereira.org.br/documents/mare/planodiretor/ planodiretor.pdf. Acesso em: 29 out 2020.

CAETANO, M. R. O protagonismo do setor privado na reforma do Ensino Médio no Brasil - o Instituto Unibanco e suas relações. In: PERONI, V. M. V.; LIMA, P. V.; KADER, C. R. (org.) Redefinições das fronteiras entre o público e o privado: implicações para a democratização da educação. São Leopoldo: Oikos, 2018. p. $147-158$.

CAMPAÑA LATINOAMERICANA por el derecho a la educación. Mapeo sobre tendências de la privatización de la educación em América Latina Y El Caribe. [s.l.]: Campaña Latinoamericana por el Derecho a la Educatión, 2015.

CARVALHO, E. J. G. Arranjos de Desenvolvimento da Educação (ADEs): instrumento de soluções colaborativas para a educação ou uma nova estratégia de expansão e de controle do mercado educacional? Currículo Sem Fronteiras, Portugal, Brasil, v. 18, p. 103-128, 2018.

COMUNICAÇÃO MILLENIUM. Turminha da liberdade lança segundo livro. [s.l.]. Instituto Millenium, 2019. Disponível em https://www.institutomillenium.org.br/factiva/turminha-da-liberdade-lanca-segundolivro/. Acesso em: 29 out. 2020.

CORMELATO, D.; MORAES, J. Alfasol e Programa Brasil Alfabetizado: a parceria público-privado nas políticas de educação de jovens e adultos. In: PERONI, V. M. V.; LIMA, P. V.; KADER, C. R. (org.) Redefinições das fronteiras entre o público e o privado: implicações para a democratização da educação. São Leopoldo: Oikos, 2018. p. 327-346.

COMERLATTO, L. P. A relação público-privada: a promessa "salvacionista" do Instituto Airton Senna (IAS) para a educação brasileira. In: PERONI, V. M. V.; LIMA, P. V.; KADER, C. R. (org.) Redefinições das fronteiras entre o público e o privado: implicações para a democratização da educação. São Leopoldo: Oikos, 2018. p. 159-170.

FERNANDES, F. Nova república? Rio de Janeiro: Zahar, 1985.

FERNANDES, F. A revolução burguesa no Brasil. 3. ed. Rio de Janeiro: Guanabara, 1987.

HARVEY, D. O neoliberalismo: história e implicações. São Paulo: Loyola, 2008.

IANNI, O. Raízes da anti-democracia na América Latina. Lua Nova, São Paulo, n. 14, p. 17-22, jun. 1988.

LACERDA, M. B. O novo conservadorismo brasileiro. Porto Alegre: ZOUK, 2019.

LAVAL, C.; DARDOT, P. La pesadilla que no caba nunca. Barcelona: Gedisa, 2017.

LAVAL, C.; DARDOT, P. Dardot e Laval: a “nova” fase do neoliberalismo. Outras Mídias, 2019. Disponível em https://outraspalavras.net/outrasmidias/dardot-e-laval-a-nova-fase-do-neoliberalismo/. Acesso em: 29 out. 2020.

LIMA, P. V. Escola sem sentido: implicações da Escola sem Partido para a democratização da educação pública. 2017. Trabalho de Conclusão de Curso (Graduação em Educação) - Faculdade de Educação, Universidade Federal do Rio Grande do Sul, Porto Alegre, 2017. 
LOWY, M. Da tragédia à farsa: o golpe de 2016 no Brasil. In: JINKINGS, I.; KLIN, D.; CLETO, M. Porque gritamos golpe. Para entender o impeachment e a crise política no Brasil. São Paulo: Boitempo Editorial, 2016. p. 61-69.

MARTINS, E. M. “Movimento Todos pela Educação”: um projeto de nação para a educação brasileira. 2013. Dissertação (Mestrado em Educação) - Faculdade de Educação, Universidade Estadual de Campinas, Campinas, 2013.

MENDES, V.; PERONI, V. M. V. Estado, mercado e formas de privatização: a influência dos think tanks na política educacional brasileira. Revista Espaço Pedagógico, 2020. p. 65-88.

MÉSZÁROS, I. Para além do capital. São Paulo/Campinas: Boitempo Editorial/Editora da Unicamp, 2002.

MOLL NETO, R. Reaganation: a nação e o nacionalismo (neo) conservador nos Estados Unidos (1981-1988). 2010. Dissertação (Mestrado em História) - Programa de Pós-Graduação em História, Universidade Federal Fluminense, Niterói, 2010.

MORAES, R. C. A organização das células neoconservadoras de agitprop: o fator subjetivo da contrarrevolução. In: CRUZ, S.; KAYSEL, A.; CODAS, G. (Org.). Direita, volver!: o retorno da direita e o ciclo politico brasileiro. São Paulo: Fundação Perseu Abramo, 2015. p. 231-246.

ORELLANA, V. La persistente mercantilización educativa y el agotamiento del progresismo en América Latina. Lecciones del caso chileno. In: PERONI, V. M. V.; LIMA, P. V.; KADER, C. R. (org.) Redefinições das fronteiras entre o público e o privado: implicações para a democratização da educação. São Leopoldo: Oikos, 2018. p. 11-29.

PERONI, V. M. V. Política educacional e papel do Estado no Brasil dos anos 90. São Paulo: Xamã, 2003.

PERONI, V. M. V. A construção do Sistema Nacional de Educação e a gestão democrática em debate In: ALMEIDA, L. C. et al. (org.). PNE em foco: políticas de responsabilização, regime de colaboração e Sistema Nacional de Educação. Campinas: Cedes, 2013. p. 1021-33.

PERONI, V. M. V. (org) Diálogos sobre as redefinições no papel do Estado e nas fronteiras entre o público e o privado na educação. São Leopoldo: Oikos, 2015.

PERONI, V. M. V. Múltiplas formas de materialização do privado na educação básica pública no Brasil: sujeitos e conteúdo da proposta. Currículo sem Fronteiras, v. 18, p. 1-27, 2018.

PERONI, V. M. V.; CAETANO, R.; LIMA, P. V. Reformas educacionais de hoje: as implicações para a democracia. Retratos da Escola, v. 11, p. 415-432, 2017.

PERONI, V. M. V.; CAETANO, M. R.; ARELARO, L. BNCC: disputa pela qualidade ou submissão da educação? Revista Brasileira de Política e Administração da Educação, v. 35, p. 35-56, 2019.

PERONI, V. M. V.; OLIVEIRA, C. M. B. O marco regulatório e as parcerias público-privadas no contexto educacional. Revista Práxis Educacional, v. 15, n. 31, jan./mar. 2019.

PERONI, V. M. V.; LIMA, P. V. Políticas conservadoras e gerencialismo. Revista Práxis Educativa, v. 15, p. $1-20,2020$. 
PIRES, D. O histórico da relação público-privada no Brasil: o enfoque jurídico. In: PERONI, V. M. V. Redefinições das fronteiras entre o público e o privado: implicações para a democratização da educação. Brasília: Liber Livro, 2013. p. 159-174.

PUELLO-SOCARRÁS, J. F. Nueva gramática del Nel-liberalismo. Itinerarios teoricos, trayectorias intelectuales, claves ideologicas. Bogotá: Universidad Nacional de Colombia, Facultad de Derecho, Ciencias Políticas y Sociales, 2008.

RIKOWSKI, G. Privatização em educação e formas de mercadoria. Retratos da Escola, Brasília, v. 11, n. 21, p. 393-413, jul./dez. 2017. https://doi.org/10.22420/rde.v11i21.810

ROCHA, C. O papel dos think tanks pró-mercado na difusão do neoliberalismo no Brasil. Millcayac - Revista Digital de Ciencias Sociales, Mendoza, Centro de Publicaciones, FCPyS, UNCuyo, v. IV, n. 7, p. 95-120, 2017.

RODRIGUES, R. O. O público e o privado na educação profissional brasileira: o caso do Pronatec. In: PERONI, V. M. V.; LIMA, P. V.; KADER, C. R. (org.) Redefinições das fronteiras entre o público e o privado: implicações para a democratização da educação. São Leopoldo: Oikos, 2018. p. 171-189.

SENNA, V. O Programa Acelera Brasil. Em aberto, Brasília, v. 17, n. 71, p. 145-148, 2000.

SUSIN, M. O. K.; MONTAÑO, M. R. A educação infantil: coisas da infância no Brasil. In: PERONI, V. M. V.; LIMA, P. V.; KADER, C. R. (org.) Redefinições das fronteiras entre o público e o privado: implicações para a democratização da educação. São Leopoldo: Oikos, 2018. p. 190-200.

THOMPSON, E. P. A miséria da teoria ou um planetário de erros. Rio de Janeiro: Zahar, 1981.

VERGER, A.; MOSCHETTI, M.; FONTDEVILA, C. La privatización educativa en America Latina: Una Cartografia de políticas, tendencias y trayectorias. Barcelona: Universidade de Barcelona, 2017.

VIEIRA, E. A. O Estado e a sociedade civil perante o ECA e a LOAS. Serviço Social \& Sociedade, São Paulo, n. 56, p. 9-23, mar. 1998.

WOOD, E. Democracia contra o capitalismo: a renovação do materialismo histórico. São Paulo: Boitempo Editorial, 2003.

\section{Sobre a Autora}

Vera Maria Vidal Peroni é professora do Programa de Pós-Graduação em Educação da Universidade Federal do Rio Grande do Sul. Doutora em Filosofia e História da Educação na Pontifícia Universidade Católica de São Paulo. Participa da Rede Latino-Americana e Africana de Pesquisadores em Privatização da Educação (ReLAAPPE). É líder do Diretório Grupo de Pesquisa Estado e políticas públicas de Educação Básica. 